\title{
AURELIO DE LOS REYES
}

INSTITUTO DE INVESTIGACIONES ESTÉTICAS, UNAM

\section{Gabriel Veyre y Fernand Bon Bernard, representantes de los hermanos Lumière, en México*}

\begin{abstract}
Principios De julio de I896, Gabriel Veyre, director técnico del cinematógrafo Lumière, y Claude Fernand Bon Bernard, concesionario para explotar el aparato en México, Venezuela, las Guayanas y las Antillas, embarcaron en El Havre para Nueva York con destino final a la ciudad de México, a la que llegaron en tren alrededor del día 24, después de cinco días de viaje en tren desde Nueva York.
\end{abstract}

* En 1972, la unam publicó mi libro Los origenes del cine en México, 1896-19oo. Desde entonces, poco se ha agregado a la información que di a conocer sobre los emisarios Lumiére en México. El presente relato, nutrido por la información hemerográfica que recopilé hace tiempo, se enriqueció con las cartas que Gabriel Veyre envió a su madre; correspondencia que amablemente me facilitó y me autorizó a publicar Philippe Jacquier, bisnieto de Veyre, quien la encontró en el desván de la casa familiar junto con unas fotografías tomadas por Veyre y un traje mexicano que compró éste, además de numerosas fotografías y objetos del viaje de Veyre a Japón. Cuando escribí el libro no había la más remota posibilidad de viajar a Lyon o a París para averiguar si aún existían películas tomadas por Veyre en México, no se conocía en México ningún libro sobre los Lumiète ni había manera de entrar en contacto con la Cinemateca Francesa o con los descendientes de los Lumière.

Posteriormente: I. Llegó a México el librito Louis Lumière, que en 1964 escribiera Georges Sadoul, en el que incluyó un apéndice con un catálogo de las películas Lumière; entre las de México no figuraban todos los títulos que recopilé en la prensa, pero en cambio incluía títulos no registrados por los diarios. 2.. Localicé programas de cine que me permitieron agregat 
En resumen, muy buen viaje. Los cinco días que pasamos en tren fueron un poco fatigantes; la noche pasada dormimos profundamente. Haré otro tanto esta noche. Desde mi ventana vi un orgue de barbarie, esto me recuerda una particularidad de mi viaje: cerca de Laredo, hasta México, existe otro árbol al que llaman órgano, lo que significa orgue,... de barbarie, ;sin duda, como los higos!

Es probable que Veyre y Bernard se conocieran y asociaran en Lyon. El cinematógrafo les ofreció la posibilidad de conocer mundo, de salir de sus fronteras; de preferir la aventura a la estabilidad.

Veyre procedía de una familia de buena posición de Lyon, ciudad donde los hermanos Lumière crearon el cinematógrafo. Su padre, notario de SaintAlban du Rhône, de la villa de L'Isere, donde vivía con su familia, a treinta kilómetros de Lyon, murió en I893. Su oficio le dio buen estatus social. Gabriel estudió farmacología porque asumió la responsabilidad de sostener a su madre, tres hetmanos y dos hermanas, pero el cinematógrafo se interpuso en su camino. Bon Bernard, personaje misterioso, parece descender de alemanes residentes en Santa Fe, Argentina. Se desconoce la razón por la cual estaba en Francia y las condiciones de su asociación con Veyre.

títulos no registrados por la prensa ni por Sadoul. 3. Conocí las películas Lumière en México que, con base en el intercambio entre cinematecas, llegaron a la sección de cine de la Biblioteca del Congreso de Washington, listadas en el apéndice, y las tres películas incluidas en el filme Lumière, exhibido en el cine club del Instituto Francés de América Latina. 4. La celebración del centenario del cine en Iyon, me permitió agregar los títulos de las películas conservadas en los archivos Lumière, todo lo cual ofrece un panorama más completo sobre la exhibición y toma de películas por los emisarios Lumière. Queda pendiente el anecdotario personal de Veyre incluido en sus cartas, de las que daré a conocer su traducción en otro espacio. No me attrevo a decir que sea el artículo definitivo sobre los emisarios Lumière en México, porque falta agregar lo que se encuentre en el archivo Lumière, cerrado a la consulta, y en otros archivos todavía no explorado, pero sí puedo esperar que su vigencia tenga una larga duración.

I. Carta de Gabriel Veyre a su madre, 25 de julio de 1896, Archivo Jacquier-Veyre (en adelante AJv), sin clasificación. "En résumé, très bon voyage. Les cinq jours que nous avons passé dans le train ont été un peu fatiguants et nous avons dormi à poing fermé la nuit passée. Je vais en faire autant cette nuit. J'entends de ma fenêtre un orgue de barbarie; ça me rappelle une particularité du voyage: près de Laredo, jusqu’à Mexico, il existe aussi un autre arbre long qu'on appelle 'órgano', ce qui veut dire orgue... de barbarie aussi sans doute, comme les figues!” Todas las traducciones son mías: A.R. 
DOI: http://dx.doi.org/10.22201/iie.18703062e.1995.67.1749

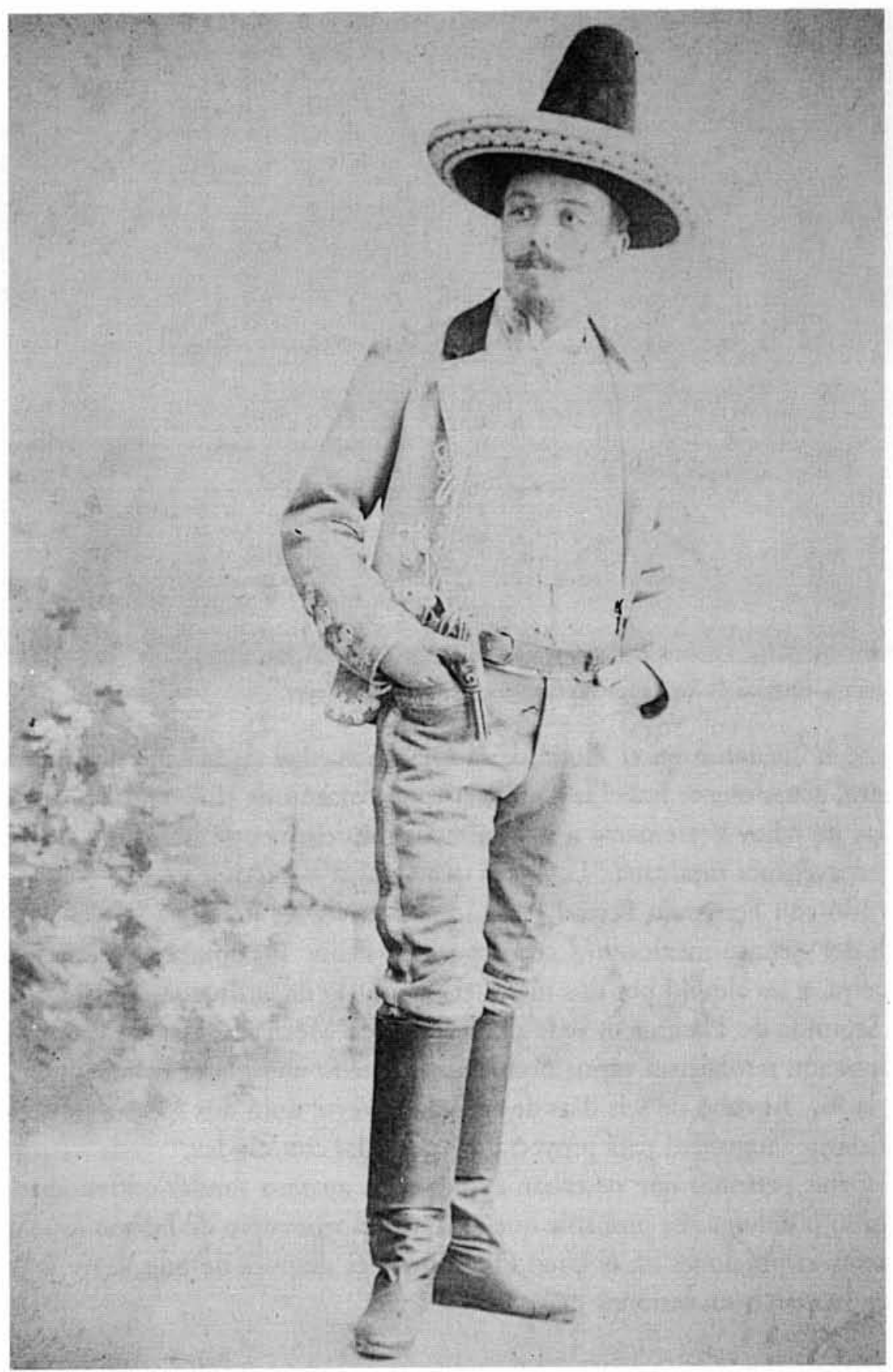

Figura 1. Gabriel Veyre con traje mexicano. Colección Jacquier-Veyre. 


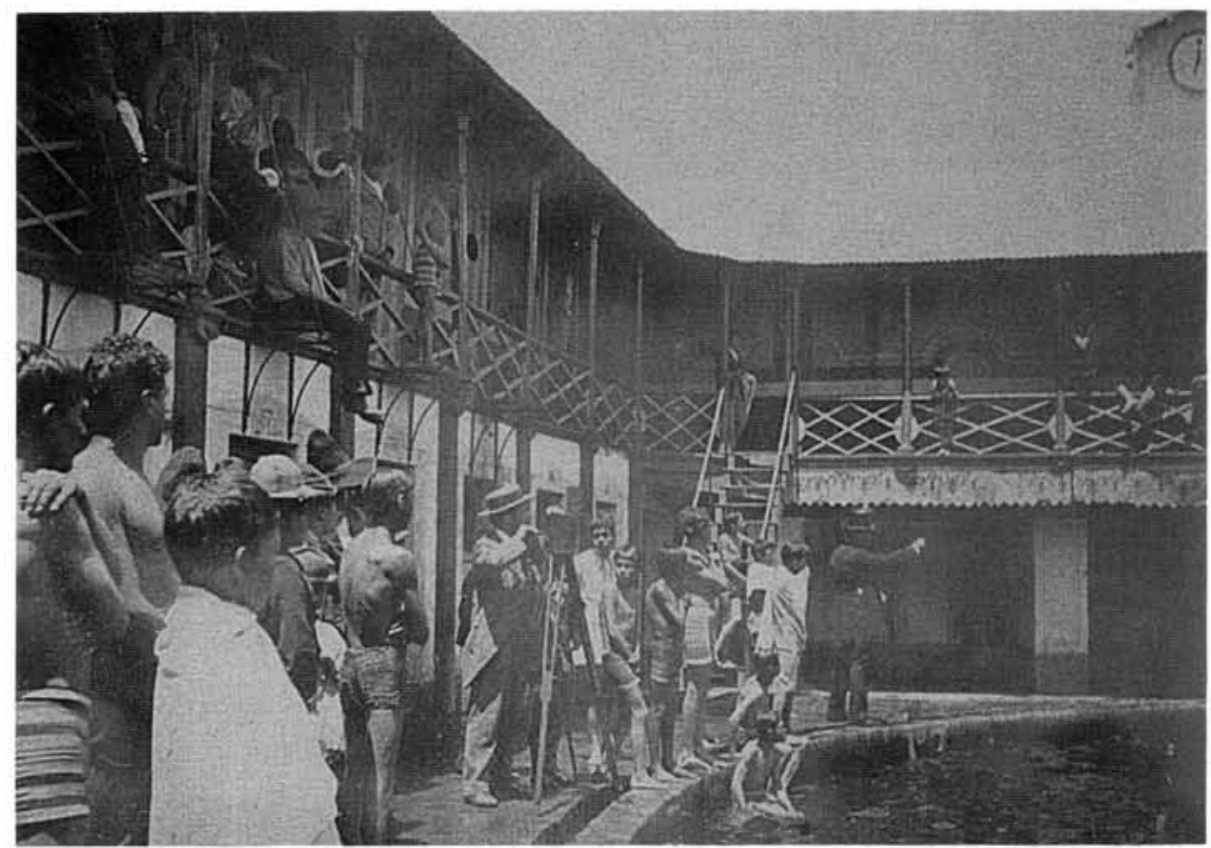

Figura 2. Interior de los Baños Pane. Colección Jacquier-Veyre.

Se hospedaron en el Hotel de la Gran Sociedad de la calle del Espíritu Santo, actualmente Isabel la Católica, en el corazón de la ciudad de México. El 25 de julio, Veyre narró a su madre las impresiones de su viaje y el inicio de su aventura mexicana. ${ }^{2}$ Le contó que alguien — no dice quién- los recomendó con Fernando Ferrari Pérez, que a su vez les presentó "al general en jefe del ejército mexicano", ${ }^{3}$ con seguridad Felipe Berriozábal, secretario de Guerra, y les alquiló por dos meses el entresuelo de la droguería Plateros, de la Segunda de Plateros 9, sede de la Bolsa de México. Antes de la primera exhibición resolvieron varios problemas técnicos, entre ellos la baja potencia de la luz. Al cabo de seis días de ansiedad, Veyre unió dos focos para lograr suficiente intensidad para proyectar las películas con nitidez. ${ }^{4}$

Otras personas que deseaban explotar un aparato similar enfrentaban el mismo problema. Es probable que se trate del vitascopio de Edison, que inició sus exhibiciones en el circo Orrín un mes después de que Veyre y Bernard iniciaran sus sesiones.
2. Ibidem.
3. Ibidem.
4. Ibidem. 


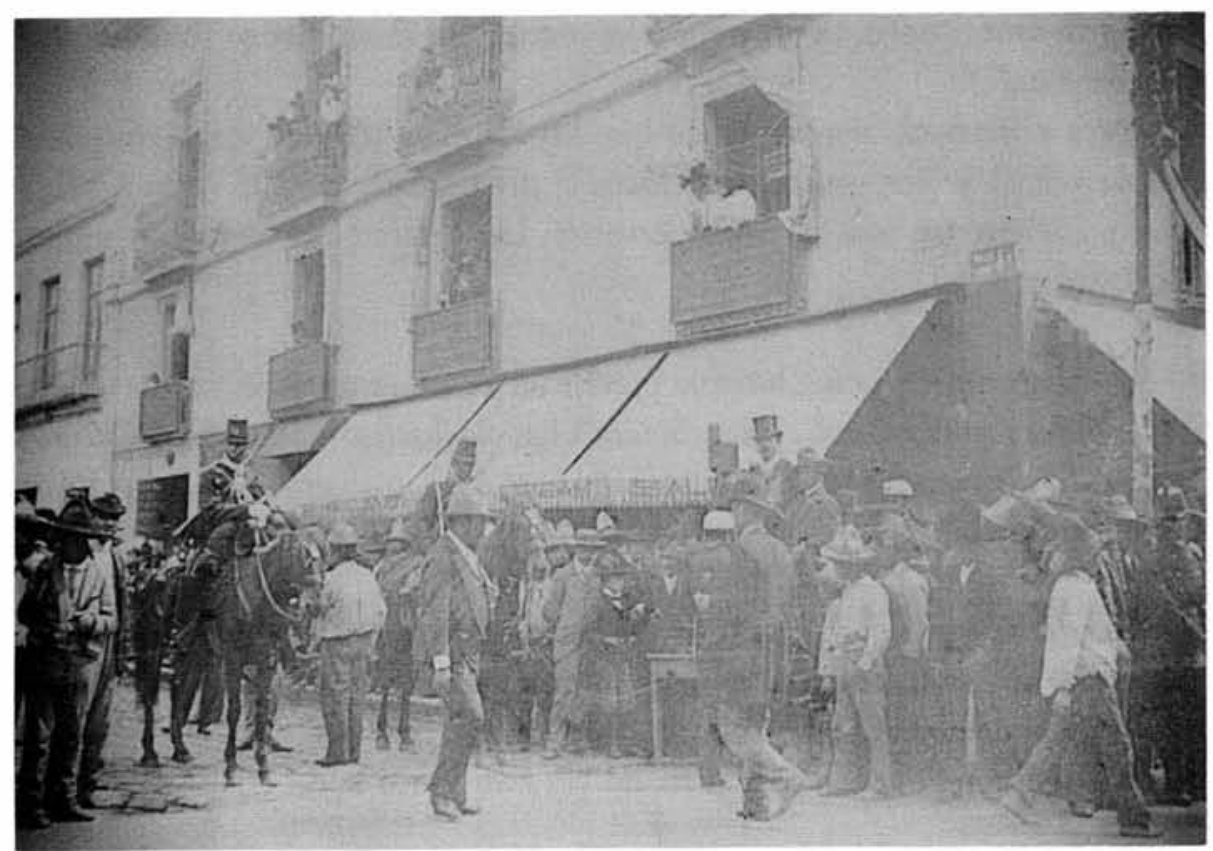

Figura 3. Veyre toma el traslado de la campana de la Independencia a su paso por la calle del Puente de San Francisco. Colección Jacquier-Veyre.

Ánimo, buena madre; confianza y paciencia. Puede ser el comienzo del fin de todas nuestras preocupaciones. 5

El primero de agosto L'Echo du Mexique, diario de la colonia francesa, acusó recibo de una invitación de dichos señores para asisitir a una exhibición del aparato, que ya había sido mostrado en las principales capitales europeas, donde provocó admiración y entusiasmo. ${ }^{6}$

El general Berriozábal les prometió efectuar ejercicios militares para que los tomaran con el aparato y gestionar una exhibición del invento al general Porfirio Díaz, presidente de la República, a quien el jueves 6 de agosto ofrecieron la primera función de cine en México, en su residencia del Castillo de Chapultepec. Asistieron el presidente, su esposa y unos 40 invitados, "quedando complacidísimos". Los anfitriones invitaron a los emisarios Lumière a

5. Ibidem. "Allons, bonne Mamman, confiance et patience, c'est peut-être le commencement de la fin de tous nos ennuis."

6. "Faits divers", en L'Echo du Mexique, sábado primero de agosto de 1896, p. 2. 
cenar y después continuaron viendo las escenas en movimiento "hasta la una de la mañana" "?

Veyre y Bernard, temerosos de que no acudiera público a la exhibición para la prensa y "los grupos científicos", ${ }^{8}$ programada para el viernes I4 de agosto, invitaron a más de i 500 personas. Llegó tanta gente que no sabían dónde metetla. ${ }^{9}$

Sus aplausos y bravos nos hicieron preveer un gran suceso, así como cada uno de sus gritos “"muy bonito!", "imuy bonito"! Las muchachas sobre todo, como diría Joseph, y los muchachos aplaudían a ultranza. En suma, una tarde de inauguración espléndida ${ }^{\text {to }}$

No se sabe qué se exhibió en la primera función, porque hubieron de llevar a cabo varias sesiones cada media hora para satisfacer la demanda. Cada programa constaba de ocho "cuadros" diferentes, que procuraban no repetir en la siguiente sesión. Un petiodista de Gil Blas contó once:

El regador y el muchacho

Jugadores de cartas

Llegada del tren

Disgusto de niños

Quemadoras de yerbas

Juegos de niños

Comitiva imperial en Budapest

Una plaza en Lyon

Bañadores en el mar

Comida del niño

Montaña rusa ${ }^{\text {II }}$

7. "En Chapultepec Sesión cinematográfica", en El Universal, sábado 29 de agosto de 1896, p. 2. 8. "El cinematógrafo de Edison en México", en El Correo Español, jueves 6 de agosto de 1896, p. 2.

9. Carta de Gabriel Veyre a su madre, I6 de agosto de I896, AJv, sin clasificación.

Io. Ibidem. "Leurs applaudissements et bravos nous font prévoir un gros succès. Chacun de s'écrier 'muy bonito', 'muy bonito'!, que c'est beau, c'est beau! Les femmes surtout (las mouchaires), comme dirait Joseph, et les moutchachos (les enfants) applaudissaient à outrance En somme, soirée d'inaugutation splendide."

II. "El cinematógrafo Lumière, la maravilla del siglo", en Gil Blas, domingo I6 de agosto de 1896, p. 3 . 


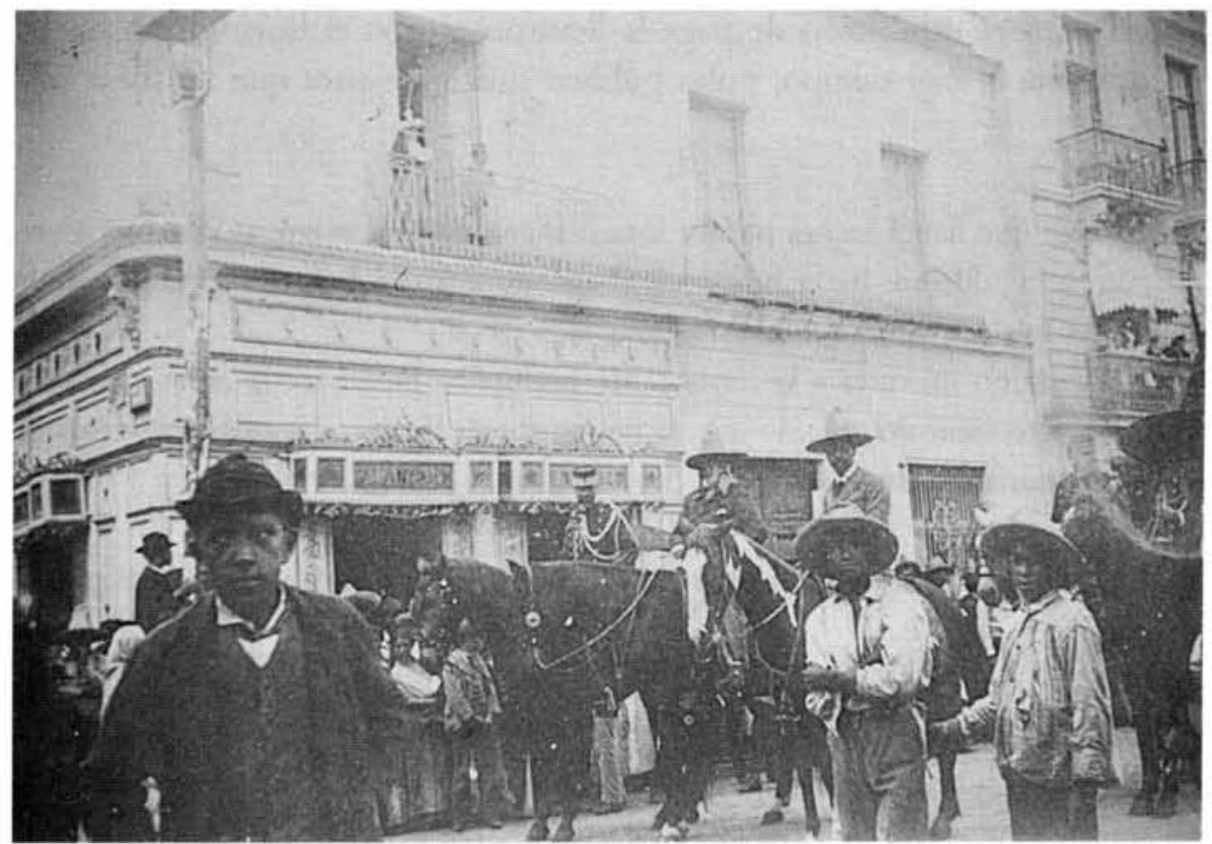

Figura 4. Los rurales a su paso por la calle de San Francisco rumbo al Zócalo. Colección Jacquier-Veyre.

El de El Monitor Republicano contó nueve:

Llegada de un tren

Montañas rusas

Una carga de coraceros

Jugadores de cartas

La comida del niño

Salida de los talleres Lumière en Lyon

El regador y el muchacho

Demolición de una pared

Los bañadores ${ }^{12}$

Es probable que el entusiasmo de los asistentes obligara a los emisarios Lumiére a exhibir más vistas de las programadas.

12. "El cinematógrafo Lumière", en El Monitor Republicano, domingo 16 de agosto de 1896, p. 3 . 
La primera exhibición de paga la llevaron a cabo el lluvioso sábado i5; no obstante el mal tiempo, hubo público suficiente para que no fuese mal negocio. ${ }^{13}$

Yo creo que habrá locura porque esta mañana muchas personas vinieron a ver, pero sólo podemos hacer funcionar el aparato a partir de las 5 de la tarde, hora en que la electricidad aumenta [...]

Termino mi carta a la carreta. Me multiplico para hacerla entre cada función, pero viene del mundo que yo no tenga más tiempo. Hemos tenido más de Ioo personas en cinco sesiones. ${ }^{14}$

En términos generales el espectáculo impresionó al público y a los periodistas.

El cinematógrafo es una especie de linterna mágica que proyecta su cono luminoso sobre una pantalla blanca colocada frente a los espectadores. En el campo luminoso de la pantalla se desarrollan escenas llenas de vida y movimiento, sorprendidas por los apatatos fotográficos del inventor $[\ldots]$

Todas las escenas son a cual más maravillosas.

En la Llegada del tren, se ve avanzar con sus movimientos naturales la locomotora seguida de los vagones de pasajeros, y a éstos desembarcar presurosos y alejarse.

La escena es tan natural, que hasta parece percibirse el ruido del tren y el murmullo de los pasajeros.

En Las montañas rusas se representa una escena semejante a la que vimos en la pantomima Un bautizo en el carnaval en el Circo Orrín: un batel que desciende

13. Carta de Veyre a su madre, I6 de agosto de I896, AJV, sin clasificación.

I4. Ibidem. "Aujourd'hui je crois qu'il y aura foule car ce matin beaucoup de personnes sont venues pour voir mais nous ne pouvons fonctionner qu’à partir de 5 heures du soir car c'est l'heure à laquelle on éclaire l'électricité [... .]

"Je termine ma lettre à la hâte. Je m'y suis mis en six fois pour la faire: entre chaque séance, mais il vient tellement de monde que je n'ai plus le temps. Sur cinq séances, nous avons plus de roo personnes." 
por una rampa y rompe el agua desgranándola en menudo rocío que envuelve por un momento la embarcación [....]

El regador y el muchacho es una escena chusca. El regador con una culebra de caucho irriga el jardín; el muchacho pisa la culebra para que no salga el agua y al observar la boca del tubo del regador, el muchacho levanta el pie y sale el agua con fuerza bañando la cara del regador [.....

En todas estas escenas están perfectamente fotografiados los movimientos: hay vida natural y animación en ellas, y todo produce un efecto por demás maravilloso ${ }^{\text {Is }}$

Diariamente se llevaban a cabo sesiones de las cinco de la tarde a las diez de la noche. El precio del boleto -elevado- era de 50 centavos, el mismo que se pagaba por asistir a sombra en los toros o en el patio del teatro Arbeu por una función de ópera. En el programa de mano, repartido a la entrada de la sala, los emisarios Lumière se mostraban orgullosos del invento:

[.... único aparato que ha podido conseguir y conservar desde hace un año, la admiración de los pueblos más ilustrados del viejo mundo. El señor presidente de la República Mexicana, general don Porfirio Díaz; el presidente de la República Francesa, señor Félix Faure; el emperador de Alemania, el zar de Rusia; la reina regente de España, en fin todas las notabilidades del mundo han aplaudido y consagrado su éxito ${ }^{\mathrm{I}}$

El espectáculo gustó; los emisarios Lumière hubieron de ofrecer sesiones todos los días. Tal parece que la heterogeneidad del público molestó a un sector de la sociedad, porque pidió funciones exclusivas todos los jueves a partir del 27 de agosto, a doble precio, un peso, por" I2 "cuadros" en lugar de ocho.

La prensa no registró el momento en que Gabriel Veyre inició la toma de escenas en la ciudad de México. El i6 de agosto, Veyre contaba a su madre que hacía unos días había impreso una vista del presidente de paseo en su parque y que el I4, el mismo día de la exhibición a los periodistas, lo había

I5. "El cinematógrafo Lumiére", en El Monitor Republicano, domingo I6 de agosto de I896, p. 3

16. Programa de mano, sin clasificación 


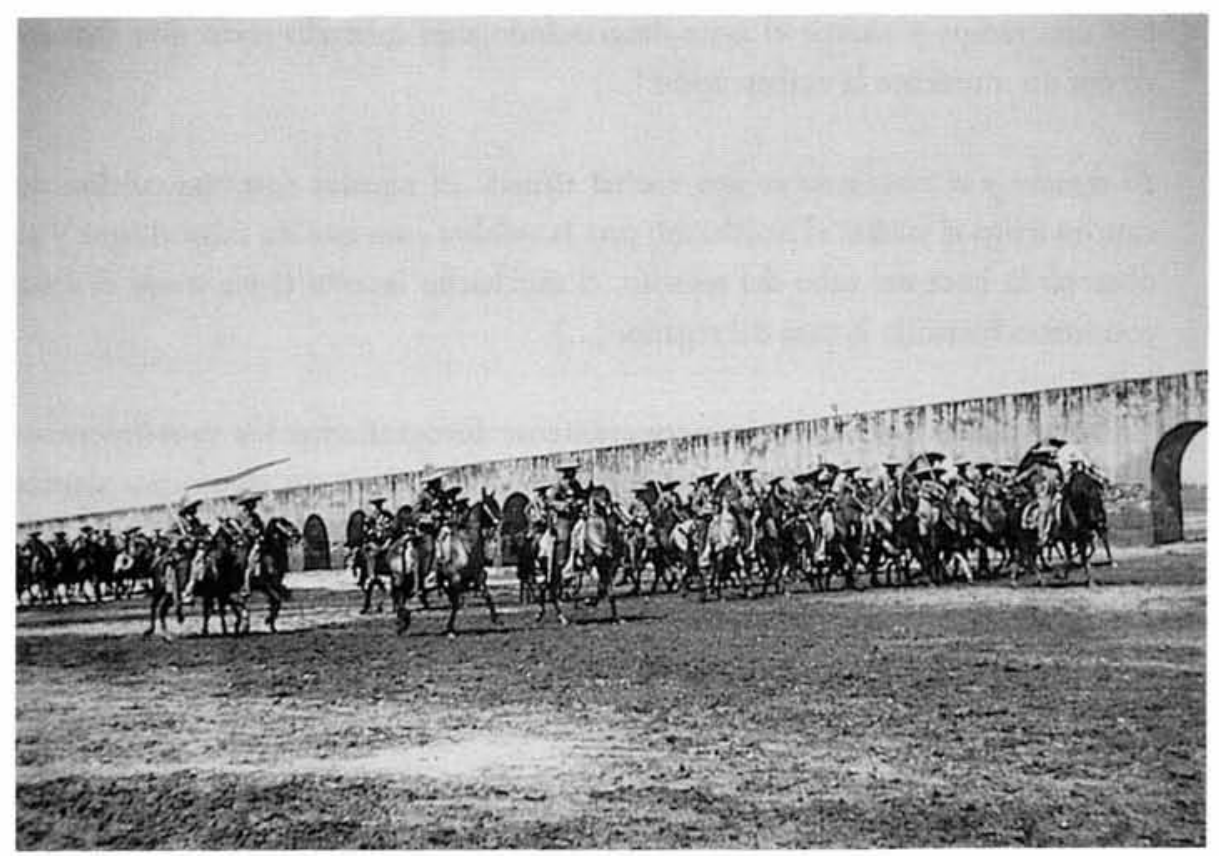

Figura 5. Los rurales posan para Veyre en el acueducto de Guadalupe. Colección JacquierVeyre.

hecho en la Escuela Militar y con unos bañistas que se echaban brincos peligrosos en el agua de la alberca Pane. ${ }^{17}$ El 18, El Correo Español anunció que próximamente se exhibiría "el retrato del señor general don Porfirio Díaz, los alumnos del Colegio Militar al practicar diversas evoluciones y otras vistas que a su presentación no nos serán desconocidas". ${ }^{18}$

El 23 mostraron en el Castillo de Chapultepec "un grupo en movimiento del $[\ldots]$ general Díaz y algunas personas de su familia, una escena en los baños de Pane, otra en el Colegio Militar y [...] una en el canal de la Viga". Gil Blas agregó que se formaría "un grupo de los literatos más conocidos de México para tomarlo en Cinematógrafo", ${ }^{19}$ pero nunca se exhibió esta película, si es que llegaron a tomarla.

Cuatro días después Veyre y Bernard regresaron a Chapultepec para mostrar El señor presidente de la República paseando a caballo en el bosque de Chapultepec, además de otros 26 cuadros de diveros temas y lugares: Pelea de

17. Carta de Veyre, 16 de agosto de 1896, AJV, sin clasificación.

18. "Noticias generales", en El Correo Españoh, martes 18 de agosto de 1896, p. 2.

19. "El cinematógrafo Lumiére", en Gil Blas, domingo 23 de agosto de 1896, p. 3. 
mujeres, Disgusto de niños, Tocinería de Chicago, Las Tullerías de París, etcétera, distribuidas en dos sesiones de 13 cuadros cada una. ${ }^{20}$

El domingo 30, Gil Blas publicó una invitación a las familias acomodadas que desearan ver reproducidos sus carruajes por el cinematógrafo, a que concurrieran al Paseo de la Reforma, entre las tres y las cuatro de la tarde, "si el tiempo está despejado, pues a esa hora se tomarán vistas del paseo, no pudiendo hacerlo más tarde por falta de luz" ${ }^{2 I}$ Se dijo que posiblemente asistirían el general Díaz y su esposa.

La gente no acudió como se esperaba; sólo doña Carmen Romero Rubio de Díaz, esposa del genetal, un grupo de familiares, "y tal vez algunos bicicletistas y peatones que por allí discurrían, fueron los únicos sacados en las fotografías instantáneas" ${ }^{22}$

Ocho días después se repite la invitación; no se tiene mayor información sobre qué hayan sacado la película, pues ésta no se programó en funciones posteriores.

El I3 de septiembre de 1896, El Tiempo comenta las nuevas películas "del señor presidente despidiéndose de sus Ministros para tomar un carruaje" y otra que muestra a "un grupo de indios al pie del árbol de la Noche Triste en Popotla". ${ }^{23}$ Agregaba que se tomarían escenas de rincones históricos de la ciudad de México y de los alrededores; sin embargo las películas no se programaron.

El Is de septiembre, Veyre captó el traslado de la campana de la Independencia a su paso por la avenida Juárez, exactamente en el tramo que entonces se conocía como el Puente de San Francisco, entre San Juan de Letrán y la calle de López. ${ }^{24}$

Se dijo que tomaron siete escenas de las fiestas patrióticas, ${ }^{25}$ pero sólo he identificado cinco: Desfile de los rurales en las fiestas patriótica, Llegada de la campana de la Independencia, El presidente de la República recorriendo la Plaza de la Constitución, Rurales a galope el 16 de septiembre y El presidente y su comitiva el í de septiembre.

Los movimientos de tropa ofrecidos por el general Berriozábal culmina-

20. Invitación, 27 de agosto de I896, Afv, sin clasificación

2.1. "El cinematógrafo en la Reforma", en Gil Blas, domingo 30 de agosto de I896, p. 2.

22. "Noticias del día", en El Tiempo, martes primero de septiembre de 1896, p. 2.

23. "Notas de la semana", en El Tiempo, domingo I3 de septiembre de 1896, pp. I y 2.

24. "La campana de la Independencia", en El Municipio Libre, miércoles I6 de septiembre de 1896 , p. I.

25. "Gacetilla", en El Tiempo, miércoles 23 de septiembre de 1896, p. 3 
ron en las películas Alumnos de Chapultepec con la esgrima del fusil, Alumnos de Chapultepec desfilando y Carga de rurales en la Villa de Guadalupe.

El I3 de octubre, Veyre imprimió escenas del fusilamiento de Antonio Navarro, "desde que el defensor licenciado González Suárez entregó la venda al presbíteto Clemente Miró, hasta que terminó la ejecución", que no exhibieron a pesar de haberlo prometido., ${ }^{27}$

El is de octubre, los emisarios Lumière iniciaron exhibiciones en el Liceo de Varones de Guadalajara. El espectáculo no constituyó una novedad porque el vitascopio de Edison se exhibía exitosamente desde el 2.6 de septiembre. Veyre viajó a la hacienda de Atequiza:

[..... a una hora de ferrocarril para tomar vistas. Tomé un lazamiento hecho por unos jinetes indios, pero el toro sale del campo de vista del aparato, por lo que se ve muy poco tiempo. Pero como los jinetes son numerosos y curiosos, creo que la vista tendrá cietto interés.

La segunda vista es un indio a horcajadas sobre un toro sin silla. El toro salta y da cornadas a diestra y siniestra para tirar al jinete. Al finalizar la vista, el toro da un buen salto y cae con todo y jinete. Esta vista será muy bella y curiosa para los europeos. ${ }^{28}$

En su carta, agregó a su madre que:

El lunes y el domingo tuvimos grandes fiestas por el día de Todos los Santos y por el día de muertos, que en este país es una fiesta nacional. Todas las calles están invadidas por pequeños comerciantes ambulantes instalados en el piso sobre un petate; por todos lados hay cabezas de muerto en azúcar que se venden a los niños, la calavera, el esqueleto, ;todo en azúcar! Muchos venden caña de

26. "Le cinématographe Lumière", en L'Écho du Mexique, miércoles I4 de octubre de I896, p. 4.

27. "Gacetilla", en El Globo, 16 de octubre de 1896, p. 3

28. Carta de Veyre, 6 de noviembre de 1896 , AJv, sin clasificación. "[... ] à une heure de chemin de fer pour prendre des vues au cinémato. J'ai pris une chasse au lasso par des cavaliers indiens, mais le taureau qu'on chasse est sorti du champ de l'appareil et ne se voit que très peu de temps. Mais comme les cavaliers sont nombreux et trés curieux, je crois que la vue gardera un certain intérét.

"La deuxième vue est un indien à cheval sur un taureau sans selle Le taureau saute et donne des coups de cornes à droite et à gauche pour renverser le cavalier. Puis vers la fin de la vue, le taureau fait un tel bon qu'il tombe avec le cavalier. Cette vue sera très belle et très curieuse pour les Européens." 


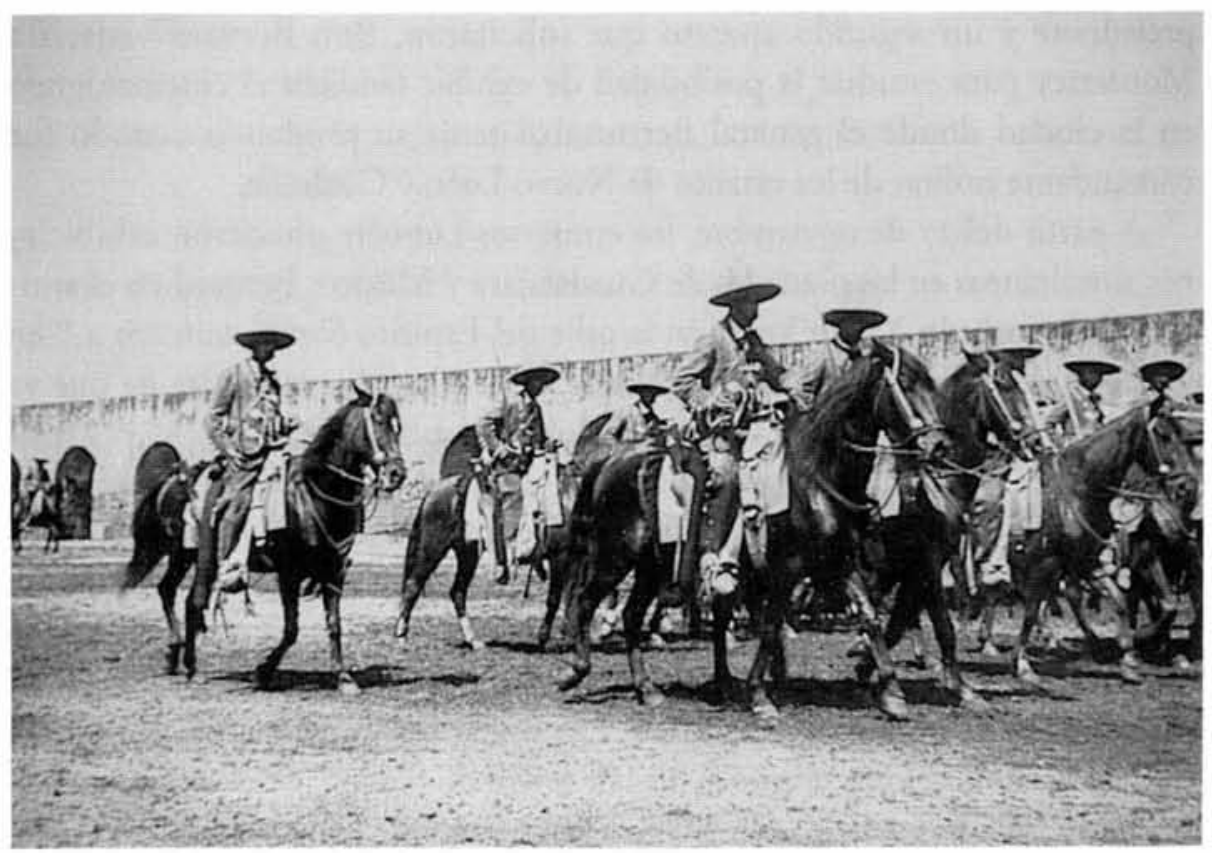

Figura 6. Los rurales posan para Veyre en el acueducto de Guadalupe. Colección Jacquier-Veyre.

azúcar que se parecen a las cañas de pescar que usábamos en Saint-Alban; se mastica este palo que tiene jugo azucarado. Me gustaría enviarte un pedazo de maíz pero no se conserva y llegaría agrio y fermentado. ${ }^{29}$

En Guadalajara tomaron Manganeo, Pelea de gallos, Un amansador, Elección de yuntas en una bueyada, Baño de caballos, ${ }^{30}$ Danza mexicana, Lazamiento de un buey salvaje y Lazamiento de un caballo salvaje, que estrenaron el 12 de noviembre.

La temporada terminó el is de noviembre, cuando Veyre regresó a la ciudad de México. Mientras llegaban de Lyon las películas que Veyre tomó del

29. Carta de Veyre, fechada en Guadalajara, 6 de noviembre 6 de 1896, Ajv, sin clasificación. "Nous avons eu dimanche et lundi de grandes fêtes ici pour la Toussaint et le jour des morts. C'est dans ces pays une fête nationale. Toutes les rues étaient remplies de petits marchands ambulants installés par terre sur un simple tapis en feuille de maïs et partout des têtes de morts en sucre qu'on vend aux enfants, des cercueils, des squelettes, le tout en sucre! Beaucoup vendaient de la canne á sucre qui ressemble aux lignes de pêche qui nous servaient à Saint-Alban et on mâche ce bois qui a beaucoup de jus sucré. Je voulais vous en envoyer un morceau mais ça ne se conserve pas et il serait arrivé là-bas aigre et fermenté."

30. "El cinematógrafo Lumière", en El Universal, domingo 6 de diciembre de 1896, p. 6. 
presidente y un segundo aparato que solicitaron, Bon Bernard viajaría a Monterrey para estudiar la posibilidad de exhibir también el cinematógrafo en la ciudad donde el general Berriozábal tenía su residencia cuando fue comandante militar de los estados de Nuevo León y Coahuila.

A partir del 27 de noviembre, los emisarios Lumière ofrecieron exhibiciones simultáneas en las ciudades de Guadalajara y México. Bernard en el antiguo Colegio León XIII y Veyre en la calle del Espíritu Santo, número $4,{ }^{31}$ en los bajos del hotel de la Gran Sociedad. Veyre platicó a su madre de que ya había hablado con su socio acerca de disolver la sociedad. ${ }^{32}$

El 25 de noviembre el general Díaz se disculpó con Veyre de no asistir al cinematógrafo, a quien éste tal vez invitó para inaugurar la nueva temporada. ${ }^{33}$ En cambio, el primero de diciembre, Carmen Romero Rubio asistió acompañada de un notable grupo femenino de familiares y amistades. El comandante militar de la ciudad de México envió la banda del cuerpo de caballería para amenizar la sesión. ${ }^{34}$ Las funciones continuaron durante el mes de diciembre y los primeros días de enero de 1897.

Entre las vistas tomadas en México por Veyre que fueron exhibidas en esa temporada se encuentran Desfile de rurales al galope, El presidente de la Republica en carruaje, regresando a Chapultepec, El presidente de la República y sus ministros en el Castillo de Chapulteper, además de Traslado de la campana de la Independencia y El presidente de la República recorriendo la plaza de la Constitución, el i6 de septiembre. ${ }^{35}$ El gobernador de palacio y la escolta de honor a caballo, ${ }^{36}$ Clase de gimnasia en el Colegio de la Paz, antiguas Vizcainas, Baile de la romeria española en el Tivoli del Eliseo ${ }^{37}$ y una película titulada Señorita Andrea, que puede corresponder al retrato de una sobrina del general Berriozábal, de quien Veyre se enamoró durante un baile, aunque según su carta se llamaba Virginia; quizá le cambió el nombre para efectos comerciales:

Te hablé de tres jovencitas que tocaban la mandolina. Destacaba una de ellas.

3I. "El cinematógrafo Lumière", en El Nacional, viemes 27 de noviembre de i896, p" 2.

32. Carta de Veyre, 6 de noviembre de 1896 , AJV, sin calisificación

33. Carta del general Díaz a Veyre, 25 de noviembre de 1896 , AJV, sin clasificación

34. "Gacetilla", en El Tiempo, miércoles 2 de diciembre de 1896, p. 3.

35. "El cinematógrafo I umière", en El Nacional, viernes 2.7 de noviembre de 1896, p. 2.

36. "Información", en El Correo Español, sábado 28 de noviembre de I896, p. 2.

37. "Gacetilla", en El Tiempo, miércoles 30 de diciembre de 1896 , p.3. 


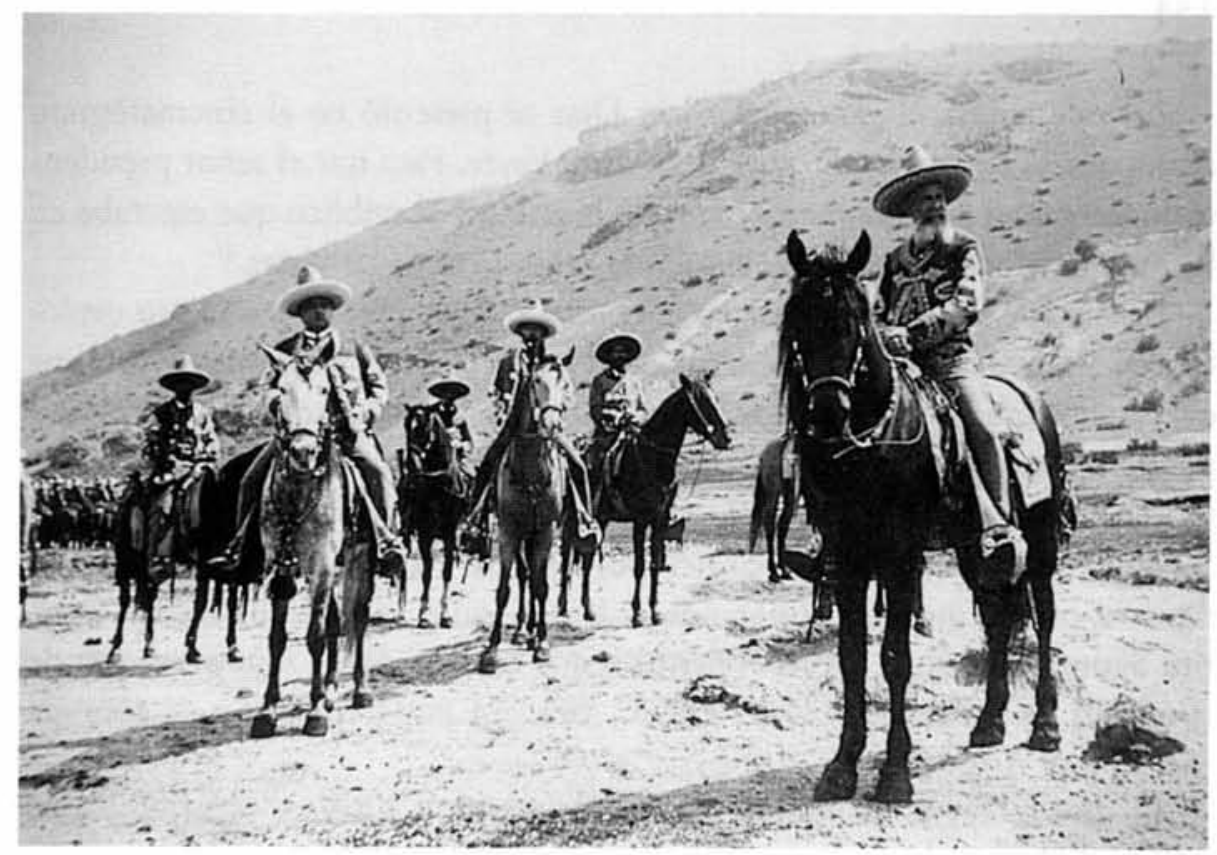

Figura 7. Los rurales posan para Veyre en el acueducto de Guadalupe. Colección JacquierVeyre.

Parece ser una de las más bonitas de México. Tiene i6 años, es la sobrina del general. Te envío su retrato, que sólo te puede dar una pálida idea de su hermosura, porque ella no sólo es bella, sino graciosa y buena. Es cierto que si en la actualidad tuviera ideas de matrimonio, es posible que la hiciera mi esposa. ${ }^{38}$

El Universal informó "que ya se tomaron fotografías de la entrada y salida a pie y en coche del señor presidente al palacio de Chapultepec" 39

La última vista que parece haber tomado Veyre en la ciudad de México corresponde a la reconstrucción de un duelo a pistola, que causó revuelo porque había tenido lugar hacía unos años entre dos diputados, uno de los cuales había muerto, y la sociedad había quedado impresionada. ${ }^{40}$

38. Fragmento de carta sin fecha, AJv, sin clasficación. "Je t'ai parlé de trois jeunes filles qui jouaient de la mandoline. L'une d'elles est remarquable. C'est, parait-il, une des plus jolies de Mexico. Elle a 16 ans; c'est la nièce du général. Je t'envoie son portrait qui ne peut te donner qu'une faible idée de sa beauté car non seulement elle est belle mais elle est gracieuse et bonne. Il est certain que si j'avais des idées de mariage aujourd'hui, il se pourrait que j'en fasse ma femme."

39. "El cinematógrafo Lumiére", en El Universal, domingo 6 de diciembre de 1896 , p. 6.

40. "Simulacro de duelo", en El Nacional, lunes I4 de diciembre de 1896, p. 2. 
El 9 de enero, el general Porfirio Díaz se presentó en el cinematógrafo acompañado de familiares, para despedir a Veyre. Para que el señor presidente pudiera estar cómodamente, se negó la entrada al público que esperaba en las puertas la hora en que comenzaría la exhibición de las vistas. ${ }^{4 \mathrm{I}}$

Bernard se quedó en México con el otro apatato pata continuar su explotación. Veyre decidió disolver la sociedad por el carácter de Bernard y porque éste se mostraba nostálgico por Santa Fe; Veyre dudaba que éste tuviera éxito porque, además de su carácter, no tenía habilidad para resolver problemas técnicos, como el de la luz; tal cosa había ocurrido a su arribo a México.

Tuvo razón, porque, al poco tiempo, Bernard vendió su aparato a Ignacio Aguirre, quien continuó explotando el aparato en el local de la calle del Espíritu Santo, número 4, según el permiso que le concedió el Ayuntamiento de la ciudad de México ${ }^{42}$ Con el dinero, Bernard pudo regresar a su añorada Santa Fe en Argentina.

El día II, Veyre, en calidad de concesionario y director técnico, partió para Veracruz en el tren de las siete de la mañana:

[....] viaje absolutamente maravilloso. Esta línea de ferrocarril es la más pintoresca del mundo. Uno desciende de lo alto de las montañas durante cerca de tres horas suspendido en los precipicios. A lo lejos se percibe una ciudad microscópica, mil metros más abajo. Vetdaderamente maravilloso. ${ }^{43}$

El vapor Lafayette lo condujo a La Habana ${ }^{44}$ Antes de partir parece haber tomado Huracán o Temporal en Veracruz, su última película en territorio mexicano $\$$

4I. "Visita del señor general Díaz", en Gil Blas, domingo ro de enero de 1897, p. 3 "

42. Archivo Histótico del Ex Ayuntamiento de la Ciudad de México, Diversiones Públicas en General, I89I-1898, legajo 9, año 1897, expediente 86I, hoja I.

43. Carta de Veyre, I5 de enero de I897, AJv, sin claisificación. "Voyage absolument maravilleux. Cette ligne de chemin de fer est la ligne la plus pittoresque du monde. On descend le long des montagnes pendant près de trois heures suspendu au dessus des précipices. $A$ un endroit, on aperçoit une ville microscopique à mille métres en dessous. C'est vraiment merveilleux."

44. Ibidem. 
DOI: http://dx.doi.org/10.22201/iie.18703062e.1995.67.1749

GABRIEL VEYRE Y FERNAND BON BERNARD

\section{Apéndice}

Películas que Gabriel Veyre tomó en México, según la prensa, programas de cine y el catálogo Lumière

I. Alumnos de Chapultepec con la esgrima del fusil

2. Alumnos de Chapulteper desfilando.

3. Un amansador, filmada en Guadalajara.

4. Baile de la romeria española en el Tivoli del Eliseo.

5. Baño de caballos, filmada en Guadalajara.

6. El canal de la Viga.

7. Carga de rurales en la Villa de Guadalupe.

8. Carmen Romero Rubio de Diaz y familiares en carruaje en el Paseo de la Reforma

9. Clase de gimnasia en el Colegio de la Paz, antiguas Viziainas.

ro. Comitiva presidencial del I6 de septiembre

II. Danza mexicand, o Jarabe tapatío, filmada en Guadalajara.

12. Desayuno de indios.

13. Desfile de rurales al galope el I6 de septiembre.

I4. Un duelo a pistola en el bosque de Chapultepec

I5. Elección de ytuntas en und bueyadd, filmada en Guadalajara.

16. Escena en los baños Pane.

17. Grupo de indios al pie del árbol de la Noche Triste

18. Grupo de los literatos más conocidos de México.

19. Grupo en movimiento del general Díaz y de su familia.

20. Lazamiento de un buey salvaje, filmada en Guadalajara.

21. Lazamiento de un caballo salvaje, filmada en Guadalajata

22. Llegada de la campana histórica el ro de septiembre

23. Manganeo, filmada en Guadalajara.

24. Huracán, o Temporal en Veracruz, filmada en Veracruz.*

* Veyte platica a su madre haber tenido buen tiempo en su viaje de Veracruz a La Habana; sin embargo, puede ser posible que el día anterior de abordar el barco hubiese un viento del norte, que agita las aguas con violencia, que por lo general desaparece al cabo de tres días, quedando nuevamente el mar tranquilo en condiciones de navegación segura. Un ambulante, cuyo proyector — no hay duda - era Lumière, la exhibió en Métida en la primera quincena de febrero de 1897, con el nombre de Huracán en Veracruz; la exhibió también con el nombre de Temporal en Veracruz, mientras que otros exhibían una película titulada Norte en Veracruz, que puede ser la misma.

La película puede ser atribuible a Veyre en tanto no se confirme que otro ambulante viajaba por México tomando películas. Veyre estuvo en Veracruz el ro de enero, mientras que la película la exhibió en Mérida el Cinematógrafo Lumière Comiste el primero de febrero, que 
25. Pelea de gallos, filmada en Guadalajara.

26. El presidente de la repuiblica despidiéndose de sus ministros para tomar un carruaje

27. El presidente de la repuiblica, en carruaje, regresando al castillo de Chapultepec

28. El presidente de la república entrando a pie al castillo de Chapultepec..

29. El presidente de la republica entrando en coche al castillo de Chapultepec.

30. El presidente de la república paseando a caballo en el bosque de Chapultepec:

3I. El presidente de la república recorriendo la plaza de la Constitución el ro de septiembre.

32. El presidente de la república saliendo a pie del castillo de Chapultepec.

33. El presidente de la republica con sus ministros el 16 de septiembre en el castillo de Chapultepec:

34. Proceso del soldado Antonio Navarro.

35. Señorita Andrea.

Peliculas tomadas por Gabriel Veyre conservadas en los Archives du Film en París*

26. Combat de coqs (Pelea de gallos).

35. Duel au pistolet (Duelo a pistola).

36. Défilé de jeunes filles au Lycée (Clase de gimnasia en el Colegio de la Paz, antiguas Vizcaínas).

345. Le Président prenant congé de ses ministres (El presidente de la república despidiéndose de sus ministros para tomar el carruaje).

346. Transport de la cloche de l'Independence (Llegada de la campana histórica el i6 de septiembie).

347. Ruraux au galop (Rurales a galope).

348. Le Président en promenade (El presidente de la república paseando a caballo en el bosque de Chapultepec).

349. Exercice à la baïonêtte (Alumnos de Chapultepec con la esgrima del fusil).

350. Lassage d'un cheval sauvage (Lazamiento de un caballo salvaje).

351. Repas dindiens (Desayuno de indios).

352. Lassage d'un boeuf savvage (Lazamiento de un buey salvaje).

353. Danse mexicaine (Danza mexicana o Jarabe tapatío).

asimismo anunciaba las películas Ejercicios militares de los cadetes de la Academia Mexicana y Una alberca en los momentos en que a ella acuden infinidad de bañistas, que corresponden a Alumnos de Chapultepec con la esgrima del fusil y a Escena en los baños Pane, ambas tomadas por Veyre. La duda de que sea de Veyre parte del escaso tiempo transcurrido entre que tomó la película y su exhibición: 29 días. Según sus cartas, el correo entre Lyon y México tardaba de 16 a 18 días, porque los barcos hacían escala en Nueva York y El Havre, a los que se deben agregar los que tomó el empresario del Cinematógrafo Comiste en su traslado a México. Quizá la comunicación entre La Habana y el puerto de Progreso era sin escala en Nueva York, y es probable que Veyre remitiese la película a Lyon desde La Habana.

* El número precedente al título de las películas corresponde al número del catálogo Lumiére. El título en español es el que consta en el resto de las fuentes. Información proporcionada por el señor Philippe Jacquiet. 
DOI: http://dx.doi.org/10.22201/iie.18703062e.1995.67.1749

GABRIEL VEYRE Y FERNAND BON BERNARD

354. Lassage des boeufs pour le labour (Elección de yuntas en una bueyada).

355. Marché indien sur le canal de la Viga (EI canal de la Viga)

356. Cavalier sur un cheval rétif (Un amansador).

357. Batgnade de chevaux (Baño de caballos).

358. Bal espagnol dans la rue (Baile de rometía española en el Tívoli del Eliseo)

La Sección de cine de la Biblioteca del Congreso de los Estados Unidos posee siete títulos, que obtuvo mediante el sistema de intercambio entre filmotecas

I. El presidente a caballo acompañado por doña Carmen, ida y vuelta frente a la cámara.

2. Rurales al galope en la Villa de Guadalupe

3. Baño de caballos en Guadalajara.

4. Pelea de gallos.

5. Lazamiento de un caballo salvaje.

6. Danza mexicana o Jarabe tapatio

7. Desayuno de indios.

Lumière, antologia de las películas de los hermanos Lumière, incluye Canal de la Viga, Traslado de la campana de la Independencia $y$ Rurales al galope. 